\title{
Introduction
}

This volume is an endeavor to shed light upon what the Japanese are like, with a focus upon their behavior in the cultural context. I hope the reader will gain a better understanding of the behavior patterns as manifested within a culture that has been generated and accumulated, taught and learned, carried and circulated, believed in and acted out by the Japanese. Before launching into the subject, I propose to spell out the general lines of orientation and the commitment of this book. The reader is requested to indulge my compulsion for getting involved in a somewhat pedagogical discourse, but the following are the theoretical and methodological foundations of the rest of the book.

ETHNOGRAPHIC BOUNDARY

The Japanese are, in countless ways, similar to other nationals, and it goes without saying that their behavior, however extraordinary it might often appear, does not go beyond the limit of humanly possible variation. It is equally important to assume that studying the Japanese should lead to a deeper understanding of human culture and behavior. It would be legitimate to observe Japanese behavior as a sample of the behavior of Homo sapiens. Let this stress upon universality be called a nomothetic point of view.

The nomothetic point of view in its extreme form has its pitfalls and weaknesses, however. I am not confident of the extent 
to which we know human universals with regard to culture and behavior. I am afraid that an observer tends to confuse his own culture with universal culture and thus tends to impose his ethnocentric interpretation upon the culture he is observing. And when he encounters something that does not appear universal at all, he might well dismiss it as nothing more than a random error. Furthermore what can be identified as definitely universal tends to be too obvious to deserve special attention. The nomothetic extreme is thus apt either to encourage the observer to commit an ethnocentric sin or to result in the generation of little information.

This book, following the ethnographic tradition, is committed to drawing a boundary of Japanese culture under the assumption that no other culture shares completely the same boundary. In this limited sense, my bias is more toward an idiographic point of view. Positively, I believe this is a more efficient approach to the area-bound culture of a national society; negatively, I am too agnostic about human culture to claim the universality of the Japanese at the outset. To be sure, it is more risky to say that the Japanese are different from the Chinese or Americans than to stress cross-cultural similarities. But I am willing to take that risk.

The concept of area-bound cultures calls our attention, furthermore, to the phenomenon of culture borrowing from other areas, particularly from neighboring cultures. It is only natural, because of such diffusion and resultant acculturation, that Japanese differ from Koreans and Chinese less than from Africans and Europeans. In addition, the Japanese are known for their eagerness to borrow indiscriminately. Despite the fact that such borrowing is likely to obliterate cultural differences, it is also known that the Japanese have maintained their identity, and that nothing has been borrowed without becoming Japanized to some degree. This provides historical justification for considering Japanese culture unique.

This idiographic commitment is not without qualifications. First, even a unique system cannot be understood unless it is viewed against general concepts and propositions. Thus, universally applicable concepts and theories derived from social science will be freely imposed in order to locate Japan uniquely in a universal map. Logically, we should start from a universal statement and proceed to a statement that identifies particular in- 
stances of Japanese culture and behavior; the latter statement, in turn, is expected to contribute to the understanding of human culture and behavior in general. Second, the claimed uniqueness of Japanese culture holds for its system as a whole, but not for all the specific sectors thereof. Taken out of the systemic context, there may well be many elements that are shared by Japanese and others alike. Unless we keep this qualification in mind, we may be tempted to read "peculiarly Japanese" into everything a Japanese does. Overexaggeration of uniqueness is another version of ethnocentrism, which allows no cross-cultural comparison. The ideological implication of "culture relativism," I believe, joins with ethnocentrism rather than opposes it as is often claimed. How, then, can we reconcile an idiographic viewpoint with crosscultural comparability? I claim that two cultures are not comparable if taken as wholes but are comparable as far as some properly selected parts of each culture are concerned.

The argument above partially overlaps with the emic-etic controversy, the controversy over the priority of either the subjective standpoint held by cultural insiders or the objective judgment by an outsider. I think that it goes right against the anthropological principle to regard the two as opposed to each other, to pit etic against emic. "Emic description requires etics, and by trying to do emic descriptions we add to our etic conceptual resources for subsequent description" (Goodenough 1968:112).

\section{Culture and Behavior}

Culture is manifested in various forms. Social anthropologists study culture as it is manifested in social institutions, such as kin groups, economic organizations, power structures, and so on. Mythology, art, literature, language, and other symbolic representations are another form. This book approaches Japanese culture from the point of view of the behavior of participants in that culture. It attempts to throw light upon the area where culture and behavior intersect. Reference to social institutions and symbolic representations may also be made, but only to illuminate Japanese behavior.

We must begin by clarifying both culture and behavior and their relationship to each other. In line with the viewpoints of Keesing and Keesing (1971), I suggest that culture is a set of general, abstract, or ideational symbols, whereas behavior is a 
series of observable, specific, muscular, organism-attached motions or postures. Behavior is a manifestation of, or a vehicle for conveying, culture. Two analytically distinct functions of culture may be suggested in relation to behavior. First, culture provides a meaning, explanation, or interpretation for an observed behavior. Culture is, then, a set of cognitive codes whereby the otherwise meaningless behavior is made meaningful. A certain behavior of a Japanese may make no sense to a foreigner until he becomes aware of that sector of Japanese culture that explains it. Second, culture gives a set of alternative directions for behavior. Involved here are a destination of behavior, namely, the goal or end to which behavior is oriented, pathways or means to reach the destination, and norms and rules controlling behavior toward that destination.

\section{Two Dimensions of Value}

In short, this book attempts to delineate a set of culturally meaningful, culturally standardized behaviors-but not all such behaviors. The Japanese person beckons to someone by a gesture similar to one that would mean goodbye among Americans; he refers to himself by pointing to his nose with his index finger, while the American tends to indicate the same by touching his chest with his thumb. These certainly represent culturally meaningful and guided behavior, but they are not relevant to my objective. I want to locate what is essential to the ordinary Japanese, to identify what their life goals are, what elates them or upsets them, what makes them happy or unhappy, pleased or angry--what "turns the Japanese on." In other words, I am interested in those aspects of cultural behavior that are "valuecharged."

What is value and how does it relate to behavior? Drawing upon theoretical contributions by Parsons and his associates (Parsons 1951; Parsons and Shils 1951), I suggest two dimensions of value, each of which is conceptualized in a dichotomy. One dimension refers to (1) the obligatory-desirable dichotomy. A value as an obligatory standard is inhibitive, and may be perceived as a constraint or burden. A value as a desirable attribute, on the other hand, corresponds with the affective aspect of behavior; it is something that carries emotional attachment, is voluntarily sought. The one is a more or less objective criterion for choice, 
whereas the other is embedded in the subjective realm. This distinction may be difficult to draw, as in the case of a wellinternalized moral standard. Nonetheless, precisely because of value-internalization, this distinction seems necessary as a means of appraising the possible range of fluctuation of a given value. A value may become manifest as a desirable in one situation, and as an obligatory or even prohibitory rule of conduct in another situation.

The other dimension of value refers to (2) the expressiveinstrumental dichotomy. A value is expressive if it is exalted as an end in itself, whereas a value is instrumental if it is considered a useful means to an end. A certain status or power position may be desired or glorified as an expressive value by some people, while others may seek it instrumentally as a means of acquiring yet another value. Even religious belief can be instrumental as well as expressive, as suggested by the Marxian label "opiate." Such variation implies the complementarity of the two aspects of value. A value cannot be instrumentally desirable unless it is expressively valuable. Using the above example, a status would have no instrumental value to one person unless it were regarded as an end value by another person. Conversely, unless the status had some instrumental utility, its expressive value would eventually decline.

\section{Conflict and Alternatives}

Once culture is defined as a repertoire of values or a hierarchy of values, it becomes apparent that no culture is conflict-free because value presupposes scarcity and involves choice. A valued object or attribute, such as wealth, status, or power, generates conflict and competition among seekers for that value because of its scarcity. One person's success in obtaining a valued object reduces or eliminates another person's accessibility to it. Furthermore, value compels the actor to make choices, decisions, and commitments. Choice of one value necessitates giving up another, perhaps equally desirable, value because "he who runs after two hares will catch neither," or "one cannot eat one's cake and have it too." Once a decision is made and the "Plan" (Miller, Galanter, and Pribram 1960) is executed, one must follow a more or less fixed course of action; one's decision becomes one's "vested interest." Both scarcity and the need for choice thus constrain action 
and generate conflict and ambivalence, which ultimately obstruct the channels for articulating, transmitting, or regularizing the value system.

This logically conceivable conflict within a culture necessitates a recognition of alternative values side-by-side with dominant values. American culture, for example, juxtaposes individualism and egalitarianism. Japanese culture places emphasis upon achievement and striving for success, but at the same time preaches the virtue of resignation and serenity. In a pioneering study of Japanese culture and personality, Ruth Benedict encountered "the most fantastic series of 'but also's' ever used for any nation of the world." The Japanese were found to be extremely polite "but also insolent and overbearing"; rigid but also innovative; submissive but not amenable to control; loyal but spiteful, and so on (1946:1-2). Japanese authors, too, have pointed out such dichotomies in Japanese culture as the samurai vs. the peasant tradition and repression vs. naturalism (Kawashima 1949; Sofue 1972). The two sets of values appear logically contradictory but seem functionally complementary or necessary. I am tempted to state a priori that Benedict's "but also's" apply not only to Japanese but to all other cultures.

\section{INTERACTION}

The foregoing discussion on values indicates my approach to this entire work. My objective is to set forth the dynamic, conflictridden interplay of the components of culture in conjunction with individual behavior. This further relates to the importance attached throughout this volume to social interaction between individuals or groups as the key linkage between culture and behavior. The reader might detect my intellectual debt to such interaction-oriented social scientists as Simmel, G. H. Mead, Goffman, and Bateson. The interaction focus should provide another explanation for variation and contrast, as well as uniformity and redundancy, in behavior from individual to individual within a culture. I will leave the task of elaborating this point to the rest of this volume. The same issue will be tackled theoretically in the concluding chapter. 